\title{
Periton Diyalizi Hastalarının Periton Diyalizinden Ayrilma Nedenleri: Tek Merkez Deneyimi
}

\author{
Reasons for Drop-Out of Peritoneal Dialysis Patients: Single Center Experience \\ Necmi Eren ${ }^{1}$, Yasin Eryılmaz ${ }^{1}$, Metin Ergül ${ }^{1}$, Nuriye Yıldız $^{1}$, Sibel Balcı ${ }^{2}$, Sibel Gökçay Bek ${ }^{1}$, \\ Erkan Dervişoğlu ${ }^{1}$, Betül Kalender ${ }^{1}$ \\ ${ }^{1}$ Kocaeli Üniversitesi Tip Fakültesi, Nefroloji Bilim Dall, Kocaeli, Türkiye \\ ${ }^{2}$ Kocaeli Üniversitesi Tip Fakültesi, Biyoistatistik ve Tip Bilişimi Anabilim Dal, Kocaeli, Türkiye
}

\author{
Yazıșma Adresi / Correspondence: \\ Necmi Eren \\ Kocaeli Üniversitesi Tip Fakültesi, Nefroloji Bilim Dal, Kocaeli, 41300, Türkiye \\ T: +905326368338 E-mail : necmi.eren@kocaeli.edu.tr \\ Geliş Tarihi / Received : 26.08.2020 Kabul Tarihi / Accepted : 06.10.2020 \\ Orcid : \\ Necmi Eren, https://Orcid.Org/0000-0002-2708-3470 \\ Yasin Erylmaz, https://Orcid.Org/0000-0001-8692-9205 \\ Metin Ergül, https://Orcid.Org/0000-0002-0706-6550 \\ Nuriye Ylldı, https://Orcid.Org/0000-0002-5815-0200 \\ Sibel Balc1, https://Orcid.Org/0000-0002-5875-7546 \\ Sibel Gökçay Bek, https://Orcid.Org/0000-0003-3325-5993 \\ Erkan Dervişoğlu, https://Orcid.Org/0000-0001-8608-7482 \\ Betül Gönüllü Kalender, https://Orcid.Org/0000-0002-3479-8300 \\ ( Sakarya Tip Dergisi / Sakarya Med J 2020, 10(4):629-635) DOI: 10.31832/smj.758001
}

Öz

Amac Türkiye'de 2018 ylı sonu itibarılya periton diyalizinin (PD) tüm diyaliz popülasyonu içindeki oranı yllar itibarıyla düšüs göstererek \%3,94 olmustur. Bu azalmanın nedenleri, yeni PD hastalarında düșüsün yanı sıra PD'den ayrılan hasta ve böbrek nakli sayılarındaki artıștır (prevalans \%21,24). Bu çalıșmada, 2010-2017 ylları arasında ünitemizde PD'den ayrılma nedenlerini araşıtırdık.

Gereç ve Çalışma PD hastalarının dosyaları gözden geçirilerek geriye dönük olarak gerçekleştirildi. Kısa PD süresi olan (<3 ay) veya takip dışı kalan hastalar çalışma dışı bırakıldı.

Yöntem Veriler SPSS 20.0 ile analiz edildi.

Bulgular Toplam 354 PD hastasının 224'ünün PD tedavisinden ayrıldığını ve dahil edilme kriterlerini karşılayan 188 hastanın (90 kadın, 98 erkek; sırasıyla \% 47,9 ve \% 52,1; ortalama yas: $53,8 \pm 15,2)$ olduğunu bulduk. Bu hastalarda kronik böbrek hastalığ $(\mathrm{KBH})$ etiyolojisi diyabetes mellitus $(66 ; \% 35,1)$, hipertansiyon $(60$; \%31,9), otozomal dominant polikistik böbrek hastalı̆̆ $(\mathrm{ODPKBH})(6 ; \% 3,2)$, primer glomerulonefrit $(6 ; \% 3,2)$, diğer ve nedeni bilinmeyen nedenler $(50 ; \% 26,6)$ olarak saptanmıştır. PD tedavisi süresi $47,1 \pm 37,0$ aydı. PD tedavisinden ayrılma nedenleri sırasılya; ölüm $(96 ; \% 51,1)$, böbrek nakli $(38 ; \% 20,2)$, peritonit $(34, \% 18,1)$, ultrafiltrasyon yetmezliği $(12 ; \% 6,4)$, hasta isteği $(2 ; \% 1,1)$, mekanik kateter obstrüksiyonu $(1 ; \% 0,5)$, cerrahi batın operasyonu $(1 ; \% 0,5)$, herni $(1 ; \% 0,5)$, plevral kaçak $(2 ; \% 1,1)$, skrotal kaçak $(1 ; \% 0,5)$ idi.

Sonuç Daha önceki calışmamızda, tedaviye dirençli peritonit ve ölümün PD'den ayrılma nedenleri arasında ilk iki sırada olduğu görülmüștü. Böbrek nakline bağlı bu oran \%4,5 idi. Ancak bu çalıșmada PD'de hastaların kalıs sürelerinin uzadığını, refrakter peritonite bağlı tedaviden ayrılma oranlarının önemli ölçüde azaldığını ve böbrek transplantasyonuna bağlı olanların arttı̆̆ını bulduk.

Anahtar Böbrek nakli; ölüm; periton diyalizi; peritonit

Objective By the end of 2018 in Turkey the ratio of peritoneal dialysis (PD) among whole dialysis population was $3.94 \%$ showing a decline in years. Besides the decrease in new PD patients, increasing number of PD drop-outs are one of the reasons of this decrease. In this study, we investigated the reasons of PD drop-out between 2010 and 2017.

We found that 224 out of 354 PD patients discontinued PD therapy and 188 patients ( $47.9 \%$ women, $52.1 \%$ men, mean age: $53.8 \pm 15.2$ years) fulfilling inclusion criteria were present. Primary etiologies of chronic kidney disease (CKD) in these patients were diabetes mellitus (66, 35.1\%), hypertension (60,31.9\%), polycystic kidney disease (6, 3.2\%), glomerulonephritis (6, 3.2\%), unknown and other reasons $(36,19.5 \%)$. The duration of PD treatment was $47.1 \pm 37.0$ months. The causes of PD discontinuation were death $(96 ; 51.1 \%)$, renal transplantation (38; 20.2\%), refractory peritonitis (32,17.3\%), ultrafiltration failure (34,18.1\%), etc., respectively.

Conclusion In our previous study we found that refractory peritonitis and death were the first two reasons of PD drop-out. However in this study, we found that the length of stay of patients on PD was increased, drop-outs due to refractory peritonitis decreased significantly and those due to renal transplantation increased.

Keywords Mortality; peritoneal dialysis; peritonitis; renal transplantation 


\section{GíRiș}

Kronik böbrek hastalığı $(\mathrm{KBH})$ tüm dünyada olduğu gibi ülkemizde de toplumu etkileyen, morbidite ve mortaliteye neden olan bir hastalıktır. Evre $5 \mathrm{KBH}$ 'da böbrek yerine koyma tedavisi olarak periton diyalizi (PD), 1970'lerden itibaren dünyada kullanılmaya başlanmış ve giderek yaygınlaşmıştır. ${ }^{1}$ Yıllar içinde kullanımı artmış ve 2008 yılında zirve yaptıktan sonra azalma trendine girmiş, 2018 yılında Dünya’ya benzer şekilde ülkemizde PD tedavisi gören hasta sayısı 3192'ye $(\% 3,94)$ düşmüştür. ${ }^{2}$ Evde uygulanan tedavi olması nedeniyle hemodiyaliz (HD) tedavisine göre hastalar açısından daha avantajlı bir tedavi şeklidir. HD tedavisinde olduğu gibi makine gereksinimi olmaması, tedavinin doğası gereği sürekli tedavi imkanı sağlaması ve kalan böbrek fonksiyonlarını HD’ye göre daha uzun süre ile koruma imkanı vermesi nedeniyle PD tedavisi bazı avantajlara sahiptir. ${ }^{3,4}$ PD tedavisinin bu avantajlarına karşın teknik yetersizlik, tekrarlayan peritonitler, ultrafiltrasyon ve diyaliz yetersizliği, hastanın kendi isteği ve KBH'da ideal tedavi olan böbrek nakli yapılması gibi nedenlerle tedaviden ayrılma görülebilmektedir. KBH'da kardiyovasküler sebeplerden sonra enfeksiyon nedenli ölümler ikinci sırada gelmektedir. Günümüzdeki yeni koronavirüs hastalığ1 (novel coronavirus, SARS-Cov2, COVID-19) salgınında ev tedavilerinin ön plana çıkması nedeniyle PD tedavisinin önemi bir kez daha ortaya çıkmıştır. Bu nedenle PD tedavisinden erken ayrılmaya neden olabilecek önlenebilir nedenlerin saptanması ve dolaysıyla engellenmesi hastaların daha uzun süre ile bu tedavide kalması sağlanabilir. Ülkemizde PD tedavisinden ayrılma nedenleri ile ilgili çalışmalar yapılmış olmakla beraber, son yıllardaki durumu yansıtan çalışma bilgimiz dahilinde yapılmamıştır. ${ }^{5} \mathrm{Bu}$ çalışmada ünitemizde 2010 yılından itibaren PD tedavisi başlanan ve bu tarihten sonra PD tedavisinden ayrılan hastaların ayrılma nedenlerinin incelenmesi planlanmıştır.

\section{GEREÇ ve YÖNTEMLER}

Çalışma Kocaeli Üniversitesi Tıp Fakültesi Etik Kurulu tarafından, 14/08/2020 tarihinde, onay No: GOKAEK-2020/13.15 ile onaylanmıştır.
Çalışmaya Ocak 2010 ve Ocak 2017 yılları arasında Kocaeli Üniversitesi Nefroloji polikliniğinde ardışık olarak PD tedavisine başlanan hastalar dahil edilmiştir. Çalışmaya alınma kriterleri olarak; PD tedavisine başlandığında 18 yaşından büyük olma, en az 3 ay süreyle PD tedavisini uygulamış olmak, verileri tam olan hastalar olarak belirlenmiştir. Toplam 354 hastaya PD tedavisi başlandığı gözlenmiş, 224 hastanın PD tedavisinden ayrıldığı gözlenmiştir. Çalışmaya alınma kriterlerine uyan 188 hastanın verileri incelenmiştir. 168 hastanın sürekli ayaktan periton diyaliz (SAPD), 20 hastanın ise aletli periton diyalizi (APD) tedavisi uyguladığı gözlenmiştir. SAPD tedavisi değişik glukoz konsantrasyonları $(\% 1,36 ; \% 2,27 ; \% 3,86)$ içeren günde 4 ya da 5 değişim şeklinde uygulanmıştır. Ultrafiltrasyon yetersizliği olan hastalara ikodekstrin solüsyonu eklenmiştir. Fizik muayene (FM), demografik, klinik ve laboratuvar verileri hastaların dosyalarından elde edilmiştir. FM, demografik ve klinik veriler PD kateter takılma tarihindeki yaş, cinsiyet, vücut kitle indeksi (VKİ), SDBH etyolojisi olarak kabul edilmiştir. Hastaların kullandıkları: eritropoetin, demir, fosfor bağlayıcı, D vitamini gibi ilaçlar ve kan üre azotu (BUN), kreatinin (Cr), kalsiyum (Ca), fosfor (P), kalsiyum fosfor çarpımı (CaxP), albümin, parathormon $(\mathrm{PTH})$, hemoglobin $(\mathrm{Hb})$, ferritin, C-reaktif protein (CRP), Total kolsterol (T. Kol), trigliserid (TG), LDL kolesterol (LDL), HDL kolsterol (HDL) gibi laboratuvar verileri hasta kayıtlarından elde edilmiştir. Günlük idrar miktarı 200 mililitrenin (ml) üzerinde olan hastalar rezidüel idrar var olarak kabul edilmiştir. Hastaların günlük peritoneal ultrafiltrasyon miktarı, tahmini glomerüler filtrasyon hızı (tGFH), haftalık Kt/V, peritoneal geçirgenlik hızı gibi veriler peritoneal eşitlenme testi (PET) verilerinden elde edilmiştir. Hastaların PD tedavisinden ayrılma nedenleri değerlendirildi ve ayrıca PD hastalarının sağkalım analizi yapild1.

\section{İstatistiksel analiz}

İstatistiksel değerlendirme IBM SPSS 20.0 (IBM Corp., Armonk, NY, USA) paket programı ile yapıldı. Sürekli değişkenler ortalama \pm standart sapma, kategorik değişken- 
ler frekans (yüzde) şeklinde verildi. Mortaliteyi etkileyen faktörleri belirlemek amaciyla ikili lojistik regresyon analizi kullanıldı. Sağkalım analizi Kaplan-Meier yöntemi ile yapıldı. İki yönlü hipotezlerin testinde $\mathrm{p}<0,05$ istatistiksel önemlilik için yeterli kabul edildi.

\section{BULGULAR}

Çalışmaya PD tedavisi başlanan ve dahil edilme kriterlerine uyan toplam 188 hasta dahil edilmiştir. PD kateter takılma tarihinde hastaların yaşı 53,8 $\pm 15,2$ (kadın: 90, \%47,9; erkek: 98, \%52,1) olarak tespit edilmiştir. KBH etiyolojisi diyabetes mellitus (DM) $(66, \% 35,1)$, hipertansiyon (HT) (60, \%31,9), otozomal dominant polikistik böbrek hastal1$\breve{g}_{1}(\mathrm{ODPKBH})(6, \% 3,2)$, primer glomerulonefrit $(6, \% 3,2)$, diğer ve nedeni bilinmeyen nedenler $(50, \% 26,6)$ olarak saptanmıştır (Tablo 1).

\begin{tabular}{|c|c|}
\hline Değişkenler & Ortalama \pm SS / n (\%) \\
\hline Yaş (yıl) & $53,8 \pm 15,2$ \\
\hline \multicolumn{2}{|l|}{ Cinsiyet } \\
\hline Kadin & $90(47,9)$ \\
\hline Erkek & $98(52,1)$ \\
\hline \multicolumn{2}{|l|}{ KBH nedeni } \\
\hline $\mathrm{DM}$ & $66(35,1)$ \\
\hline HT & $60(31,9)$ \\
\hline ODPKBH & $6(3,2)$ \\
\hline Primer GN & $6(3,2)$ \\
\hline Diğer ve nedeni bilinmeyen & $50(26,6)$ \\
\hline \multicolumn{2}{|c|}{$\begin{array}{l}\text { n: Sıklık, SS: Standart Sapma, KBH: Kronik böbrek hastalığı, } \\
\text { DM: Diyabetes Mellitus, HT: Hipertansiyon, ODPKBH: Otozom- } \\
\text { al Dominant Polikistik Böbrek Hastalığı, GN: Glomerülonefrit }\end{array}$} \\
\hline
\end{tabular}

PD tedavi süresi $47,1 \pm 37,0$ ay, PD tedavisinden ayrilma nedenleri; ölüm $(96, \% 51,1)$, böbrek nakli $(38, \% 20$ ,2), peritonit $(34, \% 18,1)$, ultrafiltrasyon yetmezliği (12, $\% 6,4)$, hasta isteği $(2, \% 1,1)$, mekanik kateter obstrüksiyonu $(1, \% 0,5)$, cerrahi batın operasyonu $(1, \% 0,5)$, herni $(1, \% 0,5)$, plevral kaçak $(2, \% 1,1)$, skrotal kaçak $(1, \% 0,5)$ olarak saptanmıştır. PD hastalarının \%20,8'nin eritropoetin, \%34,9'nun D vitamini, \%58,4'nün fosfor bağlayıcı kullandığı görüldü. Hastaların \%35,4'nün ikodekstrin, \%13,3’nün nutrineal solüsyonu kullandığı gözlendi. PD hastalarının \%53,7'sinin hızlı, \%15,7'sinin yavaş geçirgenlikli olduğu saptandı. Hastaların PD kateter takılma tarihindeki laborauvar bulguları Tablo 2'de sunulmuştur.

\begin{tabular}{|l|l|}
\hline \multicolumn{2}{|l|}{ Tablo 2: Periton diyalizi hastalarının laboratuvar sonuçları } \\
\hline Değişkenler & Ortalama \pm SS / n (\%) \\
\hline BUN (mg/dL) & $68 \pm 23$ \\
\hline Cr (mg/dL) & $6,4 \pm 3,3$ \\
\hline Hb (g/dL) & $10,2 \pm 1,8$ \\
\hline Ca (mg/dL) & $8,50 \pm 0,96$ \\
\hline P (mg/dL) & $4,7 \pm 1,6$ \\
\hline PTH (pg/ml) & $337 \pm 421$ \\
\hline Albümin (g/dL) & $3,5 \pm 0,6$ \\
\hline Ferritin (ng/mL) & $385 \pm 417$ \\
\hline CRP (mg/dL) & $2,6 \pm 7,7$ \\
\hline Total Kolesterol (mg/dL) & $178,5 \pm 45,3$ \\
\hline LDL Kolesterol (mg/dL) & $110,9 \pm 35,5$ \\
\hline HDL Kolesterol (mg/dL) & $38,9 \pm 12,7$ \\
\hline TG (mg/dL) & $142,3 \pm 73,4$ \\
\hline Rezidüel idrar volümü (ml) & $783 \pm 762$ \\
\hline Ultrafiltrasyon (ml) & $1012 \pm 521$ \\
\hline Kt/V (haftalık) & $2,1 \pm 0,8$ \\
\hline RRF (ml/dak/1,73 m2) & $6,05 \pm 6,4$ \\
\hline $\begin{array}{l}\text { SS: Standart Sapma, BUN: Kan üre azotu, Cr: Kreatinin, Hb: } \\
\text { Hemoglobin, Ca: Kalsiyum, P: Fosfor, PTH: Paratiroid hormon, } \\
\text { CRP: C- reaktif protein, LDL: Düşük yoğunluklu lipoprotein, } \\
\text { HDL: Yüksek yoğunluklu lipoprotein, TG: Trigliserid, RRF: } \\
\text { Rezidüel renal fonksiyon }\end{array}$ \\
\hline
\end{tabular}

Çalışmamızda PD hastalarının iki, beş ve on yıllık sağkalım oranları sırasıyla $\% 79,9 ; \% 56,9$ ve $\% 15,5$ olarak saptanmıştır (Şekil). İkili lojistik regresyon analizinde ileri yaş ve $\mathrm{PD}$ kateter takılma tarihindeki albümin düzeyinin mortalite üzerinde istatistiksel olarak anlamlı bir etkiye sahip olduğu saptandı (sırasıyla $\mathrm{p}<0,001 ; \mathrm{p}=0,025$ ) (Tablo 3 ). 
Tablo 3: Mortalite için risk faktörlerinin ikili lojistik regresyon analizi ile belirlenmesi

\begin{tabular}{|c|c|c|}
\hline Değişkenler & OR (\%95 CI) & $\mathbf{p}$ \\
\hline Yaş & $1,062(1,029-1,096)$ & $<0,001$ \\
\hline $\mathrm{Hb}(\mathrm{g} / \mathrm{dL})$ & $0,987(0,784-1,242)$ & 0,909 \\
\hline $\mathrm{P}(\mathrm{mg} / \mathrm{dL})$ & $0,872(0,665-1,144)$ & 0,324 \\
\hline Alb (g/dL) & $0,443(0,217-0,904)$ & 0,025 \\
\hline $\mathrm{CRP}(\mathrm{mg} / \mathrm{dL})$ & $0,971(0,832-1,133)$ & 0,704 \\
\hline \multicolumn{3}{|l|}{ Rezidüel idrar } \\
\hline$\geq 200$ & $1,553(0,622-3,877)$ & 0,345 \\
\hline Yok & 1,000 (referans) & \\
\hline \multicolumn{3}{|l|}{ Ikodekstrin } \\
\hline Yok & $1,683(0,713-3,974)$ & 0,235 \\
\hline Var & 1,000 (referans) & \\
\hline \multicolumn{3}{|c|}{$\begin{array}{l}\text { OR: Odds oranı, CI: Güven Aralığı, Hb: Hemoglobin, P: Fosfor, } \\
\text { Alb: Albümin, CRP: C-reaktif protein }\end{array}$} \\
\hline
\end{tabular}

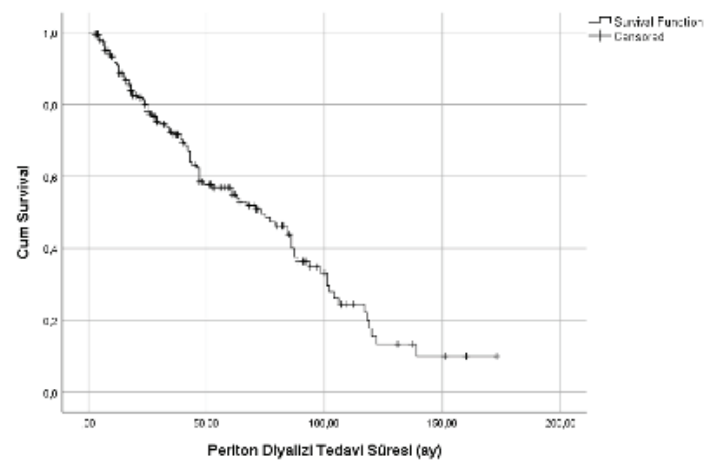

Şekil: Periton diyalizi hastalarında sağkalım oranları

\section{TARTIŞMA}

Çalışmamızda PD tedavisinden ayrılma nedenlerinin başında ölüm $(\% 51,1)$, ikinci sırada böbrek nakli $(\% 20,2)$, tedaviye dirençli peritonitin \%18,1'lik bir oranla üçüncü sırada, ultrafiltrasyon yetersizliğinin ise $\% 6,4$ ile dördüncü sırada olduğunu saptadık.

PD hastalarında peritonit, çıkış yeri enfeksiyonu gibi enfeksiyöz komplikasyonlara bağlı olarak PD'den ayrılma oranı \%28 olarak saptanmıştır. ${ }^{6}$ Ülkemizde yapılan bir çalışmada ise peritonit nedeniyle PD tedavisinden ayrılma oranı \%19 olarak gözlenmiş. Çalışmamızda bu oran $\% 18,1$ olarak saptanmış olup merkezimizde daha önce yapılan çalışmada saptanan $\% 41,8^{\prime}$ lik orana göre oldukça düşük olduğu saptanmıştır. ${ }^{5} \mathrm{Bu}$ düşüşün sağlanmasında hekimler ve PD hemşireleri ile yardımcı sağlık personelinin rolü olduğu düşünülmekle beraber peritonit oranlarının ve peritonit etkenlerinin değerlendirilmemiş olması çalışmamızın kısıtllılıklarıdır.

Hollanda'da yapılan bir çalışmada teknik yetersizlik nedeniyle iki yılın sonunda hastaların \%64'nün PD tedavisine devam edebildiği gözlenmiştir. ${ }^{8}$ Japonya’da yapılan başka bir çalışmada ise altı yıldan daha uzun bir süre ile PD tedavisi uygulayan hastalarda PD tedavisinden ayrılmanın en önemli nedeni olarak ultrafiltrasyon yetersizliği olduğu gösterilmiştir. ${ }^{9}$ Bu çalışmaların ortak özelliği ise hastalarda solüsyon olarak ikodekstrin kullanılmamış olmasıdır. Kawaguchi ve ark.'nın çalışmasında ultrafiltrasyon (UF) yetersizliği nedeniyle hemodiyalize geçiş $\% 24$ oranında iken ikodekstrinin kullanıma girmesiyle UF yetersizliği oranı çeşitli çalışmalarda \%1,7-13,7 olarak tespit edilmiştir. ${ }^{9110}$ Bizim çalışmamızda ise ikodekstrin kulllanımı \%35,4 gibi azımsanmayacak bir oranda, teknik ve ultrafiltrasyon yetersizliği ise sırasıyla $\% 0,5$ ve $\% 6,4$, bu çalışmalara göre oldukça düşük oranda saptanmıştır. Diyet uyumsuzluğu, fazla tuz ve sıvı alımı, uygunsuz diyaliz reçetelendirmesi, rezidüel renal fonksiyon kaybı durumunda reçetelendirmede uygun değişiklik yapılmaması, kateter problemleri yetersiz volüm kontrolünün sık görülen nedenleridir. PD hastalarında hipevoleminin önlenmesinde diyet uyumunun yanında özellikle RRF olan hastalarda loop diüretikleri kullanımı faydalıdır. Çalışmamızda diüretik kullanımı ve dozları değerlendirilememiştir. Yanı sıra anjiyotensin dönüştürücü enzim inhibitörleri (ACE inh'i) ya da anjiyotesnin reseptör inhibitörleri (ARB) de RRF korunmasında faydalı bulunmuştur. Çalışmamızda PD hastalarımız ACE inh’i ya da ARB kullanıp kullanmadığı ve bunların RRF korunmasında olası etkisi değerlendirilememiştir.

Kateter yer değiştirmesi ve omentum yapışıklığına bağlı mekanik komplikasyonlar PD'den ayrılmaya neden olabilmektedir. Omentopeksi, adheziyonların açılması gibi 
erken laparoskopik girişimler ile kateterdeki mekanik obstrüksiyon ortadan kaldırılabilir ve kateter kaybı engellenebilir. ${ }^{11}$ Çalışmamızda kateterde mekanik obstrüksiyon nedeniyle sadece bir hasta $(\% 0,5)$ PD tedavisinden ayrilmiştır.

Hong Kong örneğinde olduğu gibi her bir ünitede ortalama 300 PD hastası olması, ünite çalışanlarında deneyimi arttırmakta, bu da hasta sonuçlarına yansımaktadır. Bu ülkede yapılan çalışmada iki yıllık teknik ve hasta sürvi oranları sırasıyla \%82 ve \%91 olarak saptanmıştır. ${ }^{12}$ PD ünitemizde yıllar içinde ortalama olarak her zaman yüzün üzerinde hasta olması hekimlerin deneyimini arttırmış, bu da tedavi sonuçlarına olumlu yansımıştır. Bizim çalışmamızda da iki yıllık hasta sürvi oranı \%79,9 olarak saptanmıştır.

İsviçre'de yapılan 20 yıllık takip çalışmasında $(n=50)$, hastaların üçte birinin böbrek nakli nedeniyle PD tedavisinden ayrıldığı gözlenmiş. ${ }^{13}$ Dervişoğlu ve ark.'nın merkezimizde yaptığı çalışmada bu oran \%4,5 olarak saptanmış. ${ }^{5}$ Çalışmamızda ise böbrek nakli nedeniyle PD tedavisinden ayrılma \%20,2 gibi oldukça yüksek bir orana ulaşmıştır. Bu eğilim Türkiye'de yıllar içinde artan sayıda gerçekleştirilen böbrek nakli sayısı ile uyumludur.

Merkezimizde 1998-2006 yılları arasında yapılan çalışmada ölüm nedeniyle PD tedavisinden ayrilma \%40,3 oranında saptanmış iken, çalışmamızda bu oran \%51,1 olarak gözlenmiştir. ${ }^{5}$ Utaş ve ark.'nın, Sipahioğlu ve ark.'nın çalışmalarında beş yıllık hasta sağkalımı sırasıyla \%68,9 ve $\% 68,8$ olarak saptanmıştır. ${ }^{14,15}$ Tekkarışmaz ve ark’nın çalışmasında da beş yıllık hasta sağkalımı benzer şekilde \%68,1 olarak bildirilmiştir. ${ }^{16}$ Yine Sipahioğlu ve ark.'nın çalışmasında on yıllık hasta sağkalımı \%40,7 olarak gözlenmiş. ${ }^{15}$ Japonya'da yapılan bir çalışmada beş ve on yıllık sağkalım sırasıyla \%67,4 ve \%48,6 iken, Meksika'da bu oranlar \%50 ve \%29 olarak saptanmıştır. ${ }^{17,18}$ Çalışmamızda beş ve on yıllık sağkalım sırasıyla \%56,9 ve \%15,5 olarak saptanmıştır. $\mathrm{Bu}$ oranların farklı saptanmasında çeşitli faktörler rol oynayabilir. Birçok ülkenin katıldığı bir çalışmada diyaliz hastalarındaki ölüm oranlarının ülkeler arasındaki farklılığ 1 genel popülasyondaki aterosklerotik kardiyovasküler nedenli ölümler ile sıkı ilişkili olduğu gösterilmiş. ${ }^{19}$ Yine bu hastalardaki demografik özellikler (yaş, komorbid hastalıklar, genetik faktörler) de farklıdır. Yanı sıra ülkeler arasında PD hastalarında transplantasyon oranları da farklıdır. Çalışmamızda on yıllık hasta sağkalımının \%15,5 olarak saptanmasında özellikle daha genç, daha az komorbid hastalığı, dolayısıyla sağkalım beklentisi daha uzun olan PD hastalarımıza böbrek nakli yapılmış olması nedeniyle daha düşük bulunmuş olabilir.

PD tedavisi KBH'da hayat kurtarıcı bir tedavi olmakla beraber PD hastalarında yaşam kalitesi sağlıklı insanlara göre düşüktür. PD tedavisinde zamanla birlikte hasta ve hasta yakınlarında tükenmişlik sendromu meydana gelmektedir. $\mathrm{Bu}$ da PD hastalarında tedaviden ayrilmanın diğer nedenlerinden biridir. Çalışmamızda PD solüsyon değişimlerini uygulayan kişinin hasta ya da hasta yakını olup olmadığı, tükenmişlik sendromu olup olmadığg değerlendirilmemiş olup bu da çalışmamızın diğer kısıtlılıklarından birisidir.

Çalışmamızın kısıtlılıkları laboratuvar testlerinin sadece başlangıç değerlerinin alınmış olması, zaman içindeki değişimlerin değerlendirilmemiş olması. İkinci olarak hastalardaki peritonit atak sayısı, yıllık peritonit oranları ve dolayısıyla peritonit oranlarının PD tedavisinden ayrılmaya etkisinin olup olmadığının değerlendirilememiş olmasıdır. Hasta sayımızın görece yüksek olması, takip dışı kalan hasta sayımızın nispeten düşük olması ve takip süresinin uzun olması çalışmamızın güçlü yönlerindendir.

Sonuç olarak tedaviye dirençli peritonit nedeniyle PD tedavisinden ayrılma oranları merkezimizde daha önce yapılan çalışmaya göre yarıdan daha çok oranda azalmış, ultrafiltrasyon yetersizliği nedeniyle ayrılan hasta say1sı azalmış, böbrek nakli nedeniyle ayrılan hasta sayısı ise anlamlı oranda artmış olmakla birlikte PD hastalarının 
tedavide kalma sürelerinin optimal düzeyde olması için önlemler alınmalıdır.

\section{Etik kurul onayı}

Kocaeli Üniversitesi Tip Fakültesi Etik Kurulu,

14/08/2020 tarih, onay No: GOKAEK-2020/13.15 
Sakarya Tip Dergisi 2020;10(4):629-635

EREN ve Ark., Periton Diyalizinden Ayrilma Nedenleri

\section{Kaynaklar}

1. Oreopoulos DG, Robson M, Faller B, Ogilvie R, Rapoport A, deVeber GA. Continuous ambulatory peritoneal dialysis: a new era in the treatment of chronic renal failure. Clin Nephrol 1979;11:125-8.

2. Süleymanlar G, Ateş K, Seyahi N. Türkiye 2018 Yil Ulusal Nefroloji, Diyaliz ve Transplantasyon Kayt Sistemi Raporu. Ekim 2019: 1-128.

3. Shahab I, Khanna R, Nolph KD. Peritoneal dialysis or hemodialysis? A dilemma for the nephrologist. Adv Perit Dial 2006;22:180-5.

4. Saxena R, West C. Peritoneal dialysis: a primary care perspective. J Am Board Fam Med 2006;19:380-9.

5. Dervişoğlu E, Selek A, Özcan U, Kalender B. Kronik Böbrek Yetmezliği Tanıst ile Sürekli Ayaktan Periton Diyalizi Uygulanan Hastalarda Periton Diyalizinin Sonlandirlma Nedenleri. Turkiye Klinikleri J Med Sci 2007;27(2):184-8.

6. Ambruso SL, Teitelbaum I. Prevention of Peritoneal Dialysis Drop-Out. Adv Perit Dial 2018;34(2018):19-23.

7. Bilgic A, Sezer S, Ozdemir FN, Akgul A, Arat Z, Haberal M. Clinical outcome after transfer from peritoneal dialysis to hemodialysis. Adv Perit Dial 2006;22:94-8.

8. Jager KJ, Merkus MP, Dekker FW, Boeschoten EW, Tijssen JG, Stevens P, et al. Mortality and technique failure in patients starting chronic peritoneal dialysis. Results of the Netherlands Cooperative Study on the Adequacy of Dialysis. Kidney Int 1999 Apr;55(4):1476-85.

9. Kawaguchi Y, Hasegawa T, Nakayama M, Kubo H, Shigematu T. Issues affecting the longevity of the continuous peritoneal dialysis therapy. Kidney Int Suppl 1997 Nov;62:S105-7.

10. Margetts PJ, Churchill DN. Acquired ultrafiltration dysfunction in peritoneal dialysis patients. J Am Soc Nephrol 2002 Nov;13(11):2787-94.
11. Crabtree JH. Rescue and salvage procedures for mechanical and infectious complications of peritoneal dialysis. Int J Artif Organs 2006 Jan;29(1):67-84.

12. Li PKT, Szeto CC. Success of the peritoneal dialysis programme in Hong Kong. Nephrol Dial Transplant 2008 May;23(5):1475-8.

13. Gloor HJ. 20 years of peritoneal dialysis in a mid-sized Swiss hospital. Swiss Med Wkly 2003 Dec 13;133(45-46):619-24.

14. Utas C; Turkish Multicenter Peritoneal Dialysis Study Group. Patient and technique survival on CAPD in Turkey. Perit Dial Int 2001; 21:602-6.

15. Sipahioglu MH, Aybal A, Unal A, Tokgoz B, Oymak O, Utas C. Patient and technique survival and factors affecting mortality on peritoneal dialysis in Turkey: 12 years' experience in a single center. Perit Dial Int May-Jun 2008;28(3):238-45.

16. Tekkarișmaz N, Torun D. Long-term clinical outcomes of peritoneal dialysis patients: 9-year experience of a single centre in Turkey. Turk J Med Sci 2020 Apr 9;50(2):386-397.

17. Shinzato T, Nakai S, Akiba T, Yamagami S, Yamazaki C, Kitaoka T, et al. Report of the annual statistical survey of the Japanese Society for Dialysis Therapy in 1996. Kidney Int 1999; 55:700-12.

18. Cueto-Manzano AM, Quintana-Pina E, Correa-Rotter R. Long-term CAPD survival and analysis of mortality risk factors: 12-year experience of a single Mexican center. Perit Dial Int 2001; 21:148-53.

19. Yoshino M, Kuhlmann MK, Kotanko P, Greenwood RN, Pisoni RL, Port FK, et al. International differences in dialysis mortality reflect background general population atherosclerotic cardiovascular mortality. J Am Soc Nephrol 2006; 17:3510-19. 